\title{
Un escritor en Nueva York. Héctor Libertella a la distancia
}

\author{
SILVANA LÓPEZ Universidad de Buenos Aires, Argentina
}

ORCID 0000-0002-3839-707X

lopezsilvana@fibertel.com.ar

\section{Resumen}

Al poco tiempo de obtener el Premio de Novela Paidós por El camino de los hiperbóreos (1968), Héctor Libertella gana la beca para participar en el «Seminario de Escritores» de la Universidad de Iowa. Esa experiencia inicia un itinerario que traslada al escritor en el espacio, de Bahía Blanca a Nueva York, al mundo, a su última habitación en Buenos Aires. En esa itinerancia, el escritor encuentra «allá» las significaciones de «acá» y las plasma en escritura. Mi lectura crítica problematiza las nociones de «distancia», «espacio» y «espacialidad» en la escritura de Héctor Libertella y en sus figuraciones de escritor, dado que esos conceptos impregnan productivamente su proyecto literario en tanto la distancia como posición, como equidistancias entre espacios, tiempos o subjetividades, y en prácticas y discursos, como camino, espacialidades y temporalidades, transforma fijaciones y jerarquías. Libertella traza su aventura y su práctica de escritor entre lo visto, lo leído y lo escrito, lo hecho y lo proyectado, en la que deshecha, inscribe y desplaza, la poética de un programa de escritura que se tiende como un juego imprevisible de asociaciones y disociaciones.

Palabras clave: Libertella / distancia / itinerancia / desmesura / fantasma

\section{A writter in New York. Libertella from a distance} Abstract

Shortly after being awarded the Paidós Novel Prize for $E l$ camino de los hiperbóreos (1968), Héctor Libertella wins the scholarship to participate in the «Writers Seminar» at the University of Iowa. This experience begins an itinerary that transports the writer from Bahía Blanca to New York, to the world, to his last room in Buenos Aires. During this trajectory, the writer finds «there», the meanings of «here» and embodies them in writing. My critical reading discusses the notions of «distance», «space» and «spatiality» in Héctor Libertella's writing and in his figurations as a writer, since these concepts fruitfully saturate his literary project while distance as position, as equidistance between spaces, times or subjectivities, and in practices and speeches, as a path, spatialities and temporalities, transforms fixations and hierarchies. Libertella defined his adventure and his practice as a writer according to what has been seen, read, written, performed and projected, on what he discards, inscribes and displaces the poetics of a programe of writing that is laid out as an unpredictable game of associations and dissociations

Key words: Libertella / distance / itinerance / excess / ghost

Recibido: 26/7/2021. Aceptado: 10/8/2021

Para citar este artículo: López, S. (2021). Un escritor en Nueva York. Héctor Libertella a la distancia. El taco en la brea, (14) (junio-noviembre). Santa Fe, Argentina: UNL. e0052 DOI: 10.14409/tb.2021.14.e0052 
todos los «dondes» son descubiertos e interpretados por el «ver en torno» (...)

no señalados ni fijados midiendo «teóricamente» el espacio.

MARTÍN HEIDEGGER

Al poco tiempo de ganar el premio de novela Paidós 1968, por El camino de los hiperbóreos (1968), Héctor Libertella obtiene la beca para participar en el «Seminario de escritores» en la Universidad de Iowa, ese acontecimiento inicia un itinerario que lo lleva de Bahía Blanca a Buenos Aires, a Nueva York, a México, a Europa, a su última habitación de dos metros por tres «en tanto celda apretada como la horma de sus zapatos» (Libertella, 2006:105). En esos desplazamientos, el lector-escritor, su ojo crítico, encuentra «allá», sentidos de «acá» y los resignifica, los plasma en escritura. Intervalos, subjetividades o trayectos, que median entre acontecimientos y espacialidades, pueden reconocerse bajo la noción de «distancia» cuya productividad impregna la poética de Héctor Libertella, tanto en sus diseminaciones como en la potencia de las operaciones de lectura y de reescritura que dominan su textos; me propongo asediar esa noción centrándome en una lectura crítica de las maniobras que exhiben esa problematización a partir de cuatro núcleos conceptuales: itinerancia, desmesura, fantasma y distancia de rescate.

\section{Primero. Itinerancia}

En 1971, Libertella envía una carta a su amigo y colega Guillermo Quartucci, con membrete de la Universidad de Iowa:

Nueva York, 23 de febrero de 1971.

Querido Guillermo: recibí tu carta, me la mandaron desde Iowa. En realidad estoy establecido la mitad del tiempo aquí y otra mitad allá. Veo que leíste la primera nota mía de Clarín, mejor así me ahorro contarte todo lo que me pasó en los primeros meses (...) Trataré de resumirte lo más o menos oficial (...) fin de año en Nueva York, con unos tremendos cupones elegantes de nieve y varios Parties en distintas casas con distintas decoraciones. Yo metido en el centro de los homosexuales de Nueva York, visitando sus clubes de distinta especie (...) Ellos hacen descomunales parties con ácido y abundante marihuana (...) Estoy un poco podrido de todo eso (...) ahora volví a un estilo completamente distinto y oficial. Estoy charlando y comiendo con peces gordos como Rodríguez Monegal, Julio Ortega y etc. Sucede que en materia profesional las cosas me van muy bien. En Iowa me di una charla sobre cómo hacer novela épica que causó bastante revuelo, enseguida me tradujeron dos cuentos que causaron más revuelo (...) Además volví a Iowa con una idea descomunal, unir las dos últimas novelas que vos leíste, estuve trabajando como un poseso un mes, saqué capítulos, escribí otros, corregí otras cosas, salió un toco de 420 páginas, la novela total que andaba buscando, se la di a leer a gente y me dicen que el resultado final es increíble, ahora vengo a Nueva York (...) y en una fotocopiadora hice quince copias y los hemos mandado al premio Barral y al Monte Ávila, esta vez sí con grandes posibilidades. (...) Así van las cosas literarias. He conseguido por fin desmistificar todo lo que sea escritores y etcétera, aquí todo el mundo está cerca y es íntimo amigo de los Vargas Llosa o los García Márquez y etcétera. Es absolutamente fácil conversar con cualquier tipo, Ginsberg y Ferlinguetti y compañía están a mano. (Quartucci, 2016:196-197)

La carta se despliega en tres carillas en la que, además de las itinerancias literarias, cuenta los proyectos de posibles viajes, las presentaciones a becas y concursos, los trabajos de traducción 
mientras comparte la vida con toda «la picarezca» de la ciudad, desde «hippies hasta lesbianas», en un departamento en la calle 50 de Nueva York y en una casa de fin de semana frente al río Hudson, asistiendo, en sótanos y en iglesias devenidas boites, a lo último en materia de happening («Deafman's glance»), conciertos y recitales (Bee Gees, Jefferson Airplane y otros), películas (Underground, If..., Little big man, entre otras), programas de televisión, shows y partidos en el Madison Square Garden.

Libertella señala que en Nueva York ha encontrado la llave: «todo abierto por delante» (197), se lee en la carta. El desplazamiento Bahía Blanca, «manzana loca» de Buenos Aires y big apple de Nueva York provoca un estallido en las condiciones de producción, circulación y recepción de su proyecto de escritura y de sus posiciones de escritor. Sus experiencias vanguardistas -en la escritura, en el cine, en el teatro como actor y espectador, en la música y en la radio (entre otras, un programa sobre discos que realizan con Guillermo Quartucci) en Bahía Blanca y más tarde, en Buenos Aires, cuyas marcas se pueden leer en los avisos culturales de la ciudad y en los textos que componen su obra - se replican en una mirada expandida que situada, al principio de la década del 7o, en el país del Norte, mixtura y desplaza la biblioteca, las genealogías de la literatura y del arte y la práctica de la escritura. Si en el país del Sur, toda la tradición le pertenece y, entre otras operaciones de citación, intertextualidad y transgenericidad, trae a El camino de los hiperbóreos (1968) a los beatniks; en 1971, conversa con Allen Ginsberg y Lawrence Ferlinguetti. Libertella tiene veintiséis años y la impronta de ese triángulo de distancias que se entrecruza con sus proyectos e intereses, difiere y se disemina, incluso, más tarde, en una escena que narra Mauro Libertella, en Mi libro enterrado, la de una noche en la que el hijo lee al padre, un texto escrito a propósito de la muerte de Syd Barret y al final de la lectura, descubre que Héctor Libertella llora, en una de las pocas veces en la vida, escribe Mauro, que lo ve «quebrarse» (Libertella, M.:2013:43); la música y la escritura los encuentra en esos cruces e intersecciones que plantea la distancia como problematización crítica.

En 1968, Artiempo, una revista de arte y espectáculos, entrevista a Libertella, a propósito del premio Paidós. Ante las declaraciones de Héctor acerca de sus posiciones de escritor, el de ser un escritor «oficial» y «clandestino», una contradicción que no es «una lucha trágica y desgarrante, sino una coexistencia» (1968:17), Enrique Pablo Rojas Paz concluye:

En síntesis: vivir, vivir sin leyes, preconceptos o verdades inmutables, haciendo del asombro una militancia de todos los días, porque únicamente de ese modo lo cotidiano dejará de ser el dato reiteradamente igual a sí mismo para convertirse en una permanente aventura. (1968:17)

El registro de esa impronta se lee en la carta dirigida a Quartucci: Libertella vive, experimenta y escribe trastornando las distancias, los sistemas, los conceptos, no hay alto o bajo, cerca o lejos, vecino o extraño, sino un diálogo adensado entre una heterogeneidad de escenarios que articulan la tradición, lo hegemónico y lo nuevo, lo determinado, lo que acontece y lo por venir, lo oficial y lo clandestino. En ese distar y en esas distancias (de la prep. «dis» que indica división, divergencia, $\mathrm{y}$ «star» del verbo stare) que suponen trayectos e intervalos de tiempo y de lugar, posiciones en espacios, temporalidades y dimensiones subjetivas, estéticas y críticas diversas, cuyas trayectorias pueden ser trazadas en una línea de tiempo (1968-1971) y en una cartografía (Bahía Blanca-Buenos Aires-Nueva York), en tanto sucesiones y recorridos como condiciones 
necesarias del devenir que implican divergencias, acoples y coexistencias —operaciones que Libertella subjetiva en torno de una figura de escritor y de una poética一; en ese magma ardiente, en Nueva York, en la que las formas de percibir y de ser afectado se sobredeterminan, Libertella encuentra «la novela "total" que andaba buscando» (2016:196).

En el ensayo dedicado a las correspondencias entre el teatro y el espectador, en tanto «mediación», «constitución estética de la colectividad», «relación pedagógica» y sus opuestos o derivas, Jacques Rancière señala que los «animales humanos son animales distantes que se comunican a través de la selva de signos» y que «toda distancia es una distancia factual, y cada acto intelectual es (...) un camino que va aboliendo incesantemente, junto con sus fronteras, toda fijación y toda jerarquía de posiciones» (2010:17). Me interesa hacer notar con la cita que transcribo de modo incompleto - porque no pretendo relacionar el acontecer de Héctor Libertella en Nueva York con la noción de «espectador emancipado», sino especular en torno a la distancia como posición que se establece en la equidistancia entre espacios, tiempos o subjetividades en juego, en prácticas y discursos, como caminos que deshacen y transforman fijaciones y jerarquías, en ese-estar-en Nueva York que desplaza el tiempo a temporalidad,' el espacio a espacialidad —, ' cómo Libertella traza en esa ciudad, lo plasma en la carta, su aventura intelectual entre lo visto, lo leído y lo escrito, lo hecho y lo proyectado, en la que deshecha, confirma y desplaza, maniobras temáticas y formales de un programa de escritura como «juego imprevisible de asociaciones y disociaciones» (Rancière, 2010:22). Desde esa perspectiva, Libertella perturba posiciones, no las fija midiendo distancias sino, desjerarquiza unas y traza otras: «he conseguido por fin desmistificar todo lo que sea escritores y etcétera, aquí todo el mundo está cerca y es íntimo» (Quartucci, 2016:197) que se entrecruza con:

ví mucha televisión de nueva york (...) En Iowa la ví a Jane Fonda (...) En materia música me estoy matando todo el día con las últimas cosas (...) Acabo de volver de Sanctuary en el curso de esta carta, anoche se ponían ritmos bárbaros de Diana Ross y todas esas cosas, toda la gente bailando como al estilo danzas clásicas, todos sueltos con esa luz estroboscópica y una música que enloquece, una gran noche (...) Y bueno Guillermo creo que estas son todas las cosas en borbotón. (198 sic)

La intensidad de esa itinerancia Iowa-Nueva York, en los primeros años de los setenta, impacta en los textos de Libertella, la puesta en distancia del acá y el allá, lo propio, lo ajeno y sus apropiaciones, se leen tematizadas en las narraciones, aparecen en la autobiografía y en las marcas de escritura que exhiben sus especulaciones críticas y teóricas.

En el mismo año de la carta, 1971, Libertella gana el premio Internacional de Novela Monte Ávila con Aventuras de los miticistas (1971), compartido con Historias de la Calle Lincoln del escritor venezolano Carlos Noguera, un texto en el que puede leerse a qué denomina «novela total» y qué entiende por «total», una significación que remite a "general, universal y que lo comprende todo en su especie» (RAE), un «todo» que la escritura de Libertella trastorna y problematiza.

La novela narra las peripecias de Virgilio Verga y de sus personajes inventados, en un entrecruzamiento de reflexiones literarias y metaliterarias, con una incesante desoriginación de las voces narradoras. El poeta Virgilio Verga, que construye a los personajes del texto y dice uno de ellos: «todos estamos de vuelta de algún lugar del norte yanqui (...) iporque él lo quiere asíl» (1971:71-72), es la figura de la "ficción crítica» — en la que el texto se pliega sobre sí para conjugar no solo la narración de un proceso sino también la reflexión crítico-teórica sobre ese proceso-y el sujeto 
de la experimentación, de la distancia crítica, de la narración, de la reflexión teórica sobre las condiciones de posibilidades del escritor, el «creador» de los personajes de ficción y el depositario de las sublevaciones de esos personajes. Una textualidad en la que confluye el viaje como motivo narrativo, como experiencia y revelación que, si se considera la genealogía de la literatura argentina y el viaje de los escritores e intelectuales argentinos a finales del siglo XIX a Europa, Libertella desplaza ese viaje iniciático de Europa a Nueva York; asimismo, el texto exhibe el gesto vanguardista al proferir «no protesto de las tradiciones porque toda tradición es posterior a mí» (127).

Con «tonos épicos», la novela parodia las marcas de los libros de aventuras y ficcionaliza las peripecias de los miticistas, en «Mitilandia», nombre con el que se denomina a la "pampa argentina». Dividido en veinticinco capítulos que se organizan en cuatro partes: «Mitilandia», «Papá Proteo», «Últimos días del vampiro», «El ouroboros», Aventuras relata, en la primera parte, la huida de los miticistas al campo, a Mitilandia, hastiados de la vida en la ciudad; en la segunda, «Papá Proteo», el nacimiento y las biografías de los miticistas Luciano de Sodio, Ferdinando, Stanley, Raulito Riesco, Carlitos, Sebastián y de otros — Cristina, Estela, Marito, Nafka—; en la tercera, «Últimos días del vampiro», la experiencia de Virgilio Verga en "La Gran Manzana», Nueva York, el regreso a la Argentina y la huida al campo; luego, el retorno de Verga a la ciudad y la muerte, su desaparición en el «cero absoluto»; «El ouroboros», la cuarta parte narra el viaje de los miticistas, en un ouroboros mecánico, alrededor del planeta y por el universo, para caer, más tarde, en Mitilandia y volver a comenzar la aventura.

La parodia, operación en la que interviene la distancia crítica, funciona como efecto y modo de suspensión de lecturas predominantes provocando un conjunto de maniobras que articulan una escritura de segundo grado, marcando un corte, un desvío, una cesura; Aventuras de los miticistas avanza sobre la puesta en contacto de dos textualidades, una parodiada y otra parodizante, que suspende los modos de lectura de un sistema literario y reabre otros, como especula Noé Jitrik, en «Rehabilitación de la parodia» (2006). La operación despliega maniobras de apropiación, de trasplante, de imitación, de fricción y de crispación, también de lectura que inscribe la decisión de elegir qué parodiar y qué direccionalidad asumir para producir un efecto en el texto.

Libertella reescribe el tópico del campo y de la novela rural argentina, desde la ciudad y desde el «norte yanqui», trastorna el gesto de la pastoral «moderna» (Sarlo, 2007:33). La apuesta narrativa no es la del encantamiento o la nostalgia por el campo, tampoco la idea de restaurar un orden perdido, la misma exhibe una mirada subversiva, crítica y de denuncia, dado que la devastación del campo, en la provincia de Buenos Aires y en la patagonia, espacios que el texto ficcionaliza, es el resultado de las acciones de los hombres de la ciudad sobre ellos. Las figuraciones y la relación con la tradición que articula Aventuras de los miticistas, dan a leer un sistema novelesco fragmentado con una lógica circular donde la sátira, la ironía y la parodia constituyen los procedimientos dominantes, el campo es el espacio de la aventura, de los protagonistas y de la escritura, asimismo, la llanura por la que se cuela la mirada crítica del escritor ante una genealogía literaria y un sistema político económico que destruye y produce inequidades.

El viaje es hacia el «desierto», en busca de una construcción anormal y monstruosa, que en medio de la pampa ostente el mejor estilo medieval.

«Mitilandia a la vista», gritó Stanley el diecinueve de setiembre de mil novecientos sesenta y nueve a las ocho treinta de la mañana, y todos nos detuvimos con un lejano aspecto de pordioseros en éxtasis 
(...) Allá enfrente, en medio de la pobreza de siglos, mamá natura tenía una erección monstruosa, y era el castillo enmohecido, destello de viejas épocas de esplendor (...) Nos aproximamos entonces avanzando como una caravana grotesca de cojos, leprosos y tullidos, arrastrando nuestros físicos endebles y fatigados por una marcha de locura a través del desierto argentino. (Libertella, 1971:15)

El viejo castillo imponente, «rodeado de una pobreza inimaginable por tanto esplendor y frivolidad ya decrépitos», tiene un puente levadizo y un foso reseco lleno de "huesos de vacas y dromedarios» pero conserva una capilla y un aspecto monástico. Es cuidado por un matrimonio aindiado de mirada ladina que figura el motivo de los «indios», articulando el nudo temático que compone la tríada pampa-desierto-indios-blancos-ciudad, que se lee en los textos argentinos del siglo XIX y se reescriben en el XX. En oposición a la ciudad babilónica de los vicios, en el castillo se vive la era del recogimiento pero las prácticas de meditación, de auto-flagelamiento, se convierten en una farsa por el gusto de los miticistas por los excesos y, también, por las marcas de las costumbres urbanas, que produce que los miticistas se organicen socialmente en el campo como en la ciudad, con sus lacras y perdiciones. El impulso mítico se convierte en adoración del mal y de las brujerías que realizan los caseros indios. Se acelera la destrucción de esa pequeña sociedad, algo que no pueden hacer con las ciudades, y el grupo se disgrega dejando en el castillo a «los cuidadores indígenas» que los mirarían «desaparecer en el horizonte, también nosotros como un don Segundo Sombra lejano y taciturno» (1971:52).

Pero antes, en otra provocación libertelliana, los «stánleydas», al mando del miticista Stanley, salen en expedición a buscar los ancestros de los araucanos en la patagonia argentina. La campaña se narra en dos versiones: la primera, mediante una «visión» del narrador en la que el grupo atraviesa un cementerio araucano y luego lo vuela con dinamita. La segunda, en el capítulo «La llegada a Mitilandia. Fin de los tonos épicos», se relata el hallazgo de un bosque patagónico petrificado que encierra en sus profundidades un conjunto de referencias míticas: el «Jardín de los Hombres sin Tiempo» (1971:60) y el «Eje de la Tierra» (1971:61) que cifran una «Época Dorada»; luego, el crepúsculo de los dioses, el nuevo advenimiento y la reconquista. Stanley, con el oído perforado por la explosión de la dinamita, en el capítulo siguiente, regresa en tren a la civilización y su última impresión de los araucanos es la de un grupo de alcohólicos y tuberculosos diseminados en la miseria. El jardín de los hombres sin tiempo, alucinado o soñado, es ahora tierra cultivada, apropiada e industrializada: «Producción y progreso» (1971:63) se lee en el texto como crítica al proyecto liberal argentino. ${ }^{3}$

La reescrituras y ficcionalizaciones de los motivos rurales se leen también en el relato de la ida al campo de Virgilio Verga, en «Últimos días del vampiro»: la noche campera, la reunión de peones, el incendio, el trabajo del arriero figurado por un Virgilio niño que falla en su tarea como lo hacen los señores de la ciudad que bajan al campo a hacerse los gauchos. La mirada sobre el campo es corrosiva, no hay riquezas ni abundancia sino una tierra seca y restos derruidos. El campo no es el espacio mítico ni el espacio del ocio y el trabajo, solo quedan las ruinas del estagnamiento. ${ }^{4}$ Por fuera de las paredes del ruinoso castillo reina el desierto, pero no el que hay que poblar como proponía la generación del treinta y siete, sino el llevado a la ruina por la explotación:

Ahora el poderío sin fronteras se empieza a volcar sobre sí mismo, la meditación última del señor feudal, en la cúspide de su gloria el fuego se come a sí mismo, se destruye con una lentitud ceremonial; después 
de saltar la ventana y gozar los primeros calores, ahora el nihilismo, un acto de majestad en el momento mismo de la perdición. El campo ya está destruido, sólo quedarán cenizas y escombros en la madrugada de escarcha (destruirse en silencio, ah, en el momento de la digestión el fuego realizó su gloria más añorada).

Mañana habrá otra vez pajaritos en el campo (...) reconstruirá todo porque la comida es excesiva y los estómagos tienen un solo límite: contemplar la perfección de su hartazgo, la intensidad de sus úlceras. (1971:158-159)

La tensión crítica se desvía por el cambio de tonos y registros, en la recurrencia a diminutivos, al humor, al choque entre vocablos. La pretendida vuelta al campo fracasa. La ciudad tiene una doble valencia en el texto, es la Babilonia fenicia pero también el espacio que permite la mirada crítica y la vampirización de los dispositivos culturales. Frente a un estado de la sociedad de la ciudad y de su economía, la literatura, críticamente, ha recurrido al tópico de «la Edad de oro» como reconstrucción de la memoria de un pasado desde el que se evalúa el presente. Trastornando la tradición literaria, Libertella reescribe sus tópicos, ${ }^{5}$ gravita aquí la triangulación Bahía BlancaBuenos Aires-Nueva York de Héctor Libertella y de «Virgilio Verga» y sus «miticistas»: la ficcionalización del regreso parodia la decadencia del esplendor de la oligarquía terrateniente e invierte el objetivo de la campaña del desierto: los habitantes de la pampa son los indios, por lo tanto, ellos se quedan en el castillo y el viaje a la patagonia se rescribe para recuperar los antepasados araucanos y críticamente poner de relieve su destrucción.

Bahía Blanca-Buenos Aires-Nueva York no es el único itinerario que realiza Libertella, viaja a Europa, vuelve a Nueva York, vive en México, en esos traslados, el escritor funda un espacio y una genealogía. En El paseo Internacional del perverso (1990), ficcionaliza lo que he denominado un espacio-puerto: «Ingeniero White», que es el "culo» pero también el orificio de salida al «mundo» (47). Ese espacio-puerto, ubicado en el centro del mapa del proyecto libertelliano, que dibuja Eduardo Stupía a pedido de Libertella, es el centro de la rosa de los vientos que conecta, mediante líneas de comunicación numeradas, hacia el noroeste, la «35», con Buenos Aires, New York, Londres, París; al nor-noroeste, la "33", con Hawaii (sic) y Baden-Baden; al oeste, la «22», con Puerto de Palos y Las Vegas; hacia el sur con Veracruz y al sureste con Madrís (sic). El mar no aparece en el mapa, su referencia está presente por omisión ya que "Argentina» mira de frente al «Océano Atlántico» y todo el país «depende del mar» (19). Al tiempo que construye ese espacio-puerto, mediante desvíos y apropiaciones de posiciones y distancias, Libertella configura una genealogía de artista, per-verso, patrilineal, afirmada, en ese texto, en la historia de la inmigración argentina y el plus de una mirada de escritor que ve, en su abuelo italiano, el pasado exótico de lo «etrusco» (100).

Ubicado en el vórtice del cruce de distancias no euclideanas, en la que se intersectan los acontecimientos históricos del continente y sus historias de dependencia,

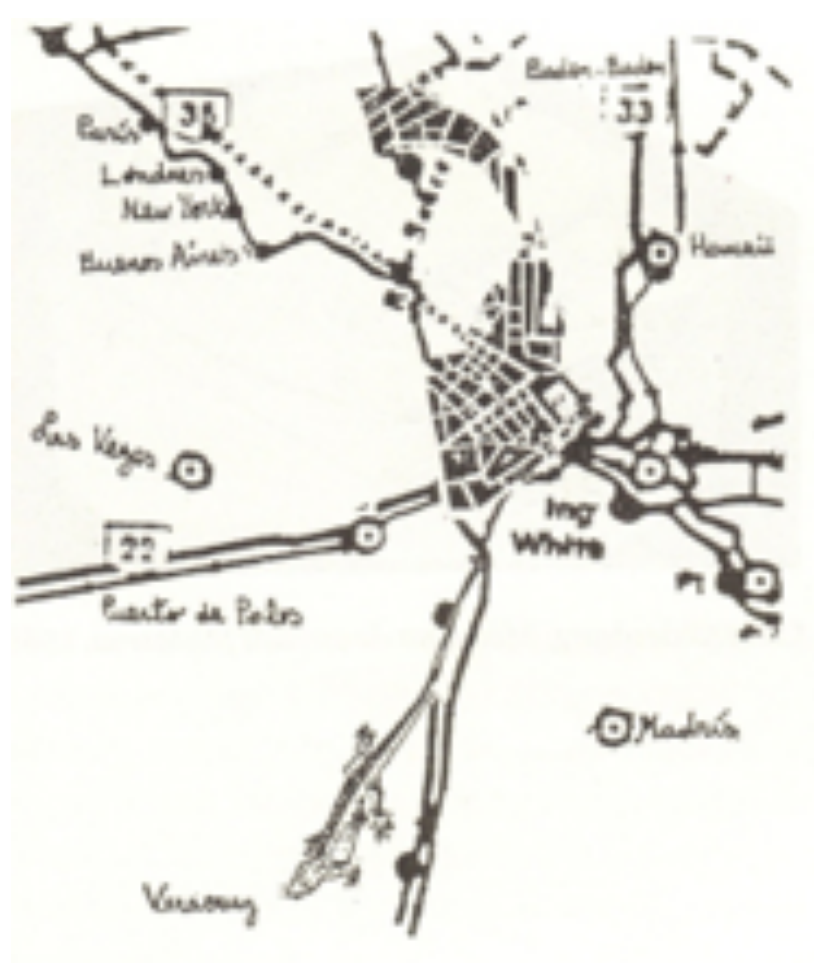


una poética y figuraciones de escritor, Libertella conjura la escritura del cavernícola, del hermético y la del corte argentino. Se lee en su texto, La librería Argentina (2003):

En el barrio neoyorquino de Queens, como en otras ciudades del ancho mundo, ciertas carnicerías exhiben pizarrones con el dibujo de vacas cuidadosamente seccionadas por líneas de puntos. Un título grande — ¿marca de fábrica? — debajo de la vaca dice: EL CORTE ARGENTINO. (28)

Faenar es la práctica carnicera distintiva del escritor argentino: vampirismo, desvío, apropiación de la cultura, transmutación de lo exótico en lo nacional y a la inversa; reescritura y trastorno de la tradición, autobiografía y la transbiografía, son estrategias de escritor que se relacionan con otra productividad que Libertella teoriza, la de, no una lectura de la tradición sino una «tradición de lectura» que en la literatura argentina trasmigra en El Matadero de Esteban Echeverría, en The Buenos Aires affair de Puig, en La Bolsa de Martel o en El uruguayo de Copi. El «corte argentino» es una operación que resulta de las maniobras de lectura, apropiación, desvío y reescritura, que se articula con las prerrogativas de escritor, la escritura y la distancia entre esos entrecruzamientos. El modo con el que Libertella construye los tiempos, los espacios y las subjetivaciones, dialoga con la «novela total» pero no como representaciones de un «todo» (RAE), sino por sus imposibilidades, de las que dan cuenta los procedimientos literarios que exhiben y despliegan sus textos.

\section{Segundo. Desmesura}

Jean Luc Nancy sostiene que el espacio público se ha agrandado con el mundo de la comunicación que ha instalado una paradoja: a mayor conexión, mayor impersonalidad; y por ello, es necesario marcar un «límite» debido a que, para poder abrir, es imperioso cerrar. En ese espacio desmesurado, algunos puntos de referencia se borran y no es posible pensar en progreso ni en regresión, sí, en transformación (Moreno Romo, 2013:195-197).

En el 2000, Libertella publica El árbol de Saussure en cuyo epílogo se lee: «el mundo tiende a la desaparición del signo». Un único árbol domina el centro de la plaza del ghetto, al que los parroquianos del bar miran embobados, apoyados en la barra de metal; a su sombra, y con la copa llena «de loros» (2000:53), duerme un escritor acurrucado «que sueña y se queda pensando: anoche vi a mi lector del futuro. Era un hombre contraído en su sillón, pinchándose las venas con una lapicera Parker» (30).

El texto tematiza lo que Libertella viene horadando desde su primera novela: la perturbación y desaparición del signo de la presencia, el árbol — paradigma de la lengua y de la lingüística saussuriana - ya no liga nada con nada, y, entre el epígrafe y el último capítulo del texto, «El futuro ya fue». El árbol de Saussure postula que las cosas «están abandonadas a su ser así» (97) y la literatura es, fue, será, sería, «la memoria retrospectiva de lo que vendrá» (2000:99); suspendidas las nociones ordinarias del tiempo en pasado, presente y futuro, la literatura «es el sonido que todavía no se produjo» 0 «que jamás ocurrirá» (100).

Ese ser «así» es, entre otras cosas, el árbol que se esfumó como idea, sujeto a su ser «eso», al «tal cual es", sin nada que lo ligue a nada, sin ninguna "propiedad», una variación del nada-NadieAlguien, resonancias de El mono gramático de Octavio Paz que Libertella transcribe en Las sagradas escrituras, y que, apropiado, reescrito y desplazado, se convierte en Árbol, en el inicio del siglo XXI, en un «ser así». Asimismo, el «así» es cita de la lectura de La comunidad que viene de Giorgio 
Agamben: ${ }^{6}$ «Cuál será — se pregunta Giorgio Agamben— la condición de la naturaleza después del Juicio Universal? Las cosas permanecerán así como son, irreparablemente, pero justamente ésta sería su novedad, ser justo y sólo su así» (Libertella, 2000:97 sic).

Las cosas abandonadas a su "ser así» quedan sujetas a «su ser eso», «sin nada que lo ligue a nada» (Libertella, 2000:98). El árbol, que en las primeras páginas del texto modifica a los parroquianos del bar, ya no lo hace porque «la cadena se detuvo», impregnada por la noción de «cualsea», una singularidad sin propiedad o pertenencia que se retoma como «el ser-cual», en su ser tal cual es. El texto de Agamben y la «cita» libertelliana rescriben sobre la huella de las categorías de Friedric Nietzsche, el «cualsea» se adviene al por-venir y la «nada» del árbol figura la vacuidad de toda coseidad. «Nada», como producto de una estructuración antes de toda propiedad, de toda pertenencia, replica en el «cero» que Libertella enuncia y persigue, que menciona en Aventura de los miticistas — «debemos volver a cero» (137); ese cero también se teje en la idea de lo "previo y póstumo, alfa y omega» (128) — y es el que reescribe en la última carta a Lorenzo García Vega con la que cierra su autobiografía: «Así que acá estoy, aislado (...) reescribiendo (...) Rumbo al impalpable cero» (2006:105).

¿Cómo leer la frase «la memoria retrospectiva de lo que vendrá»? ¿Qué es lo que vendrá habiendo sido? ¿Qué está adelante y qué, atrás? ¿Hay adelante y hay atrás en un estallido de las dimensiones del espacio, en un encimado de tiempos, en las subjetividades, cuando el mundo tiende a la desaparición del signo?

En el ghetto de El árbol de Saussure vive un ejemplar asexuado, el «mono rhesus», — «un raro ejemplar que anda por la selva sin apetito de macho y hembra» (2000:23) — que articula significancias en trabajo: «falla genética» (por manipulación humana de cromosomas), «hembro», «tipo a-específico», «minoría de minorías», «sexo marginal» (2000:23), varón-varona, constitución «neutra» de química literaria (2000:24). El mono quiere salir a recorrer la jungla pero no sabe cómo porque los bordes de la mancha, en la que se constituye el ghetto, no delimita una muralla ni una línea que permita pensar un «afuera» (35) y un adentro, no hay «afuera» del ghetto — como no hay afuera del texto—- porque la espacialidad está trastornada: «La noción de Aldea será superada, es cierto, por los espacios extraños en los que nos encontremos. Pero si verdaderamente somos nosotros los extraños, entonces la noción misma del Espacio habrá sido superada (2000:37)». El mono callejea y los parroquianos ven a ese hembro, que construye «la crónica de un cartógrafo» (2000:36) cuyo deseo de «salir» es tan grande que es posible que «el ghetto sea más grande que la Aldea Global como conjunto» (2000:35). ${ }^{8} \mathrm{El} \mathrm{mono} \mathrm{camina} \mathrm{por} \mathrm{un} \mathrm{mapa} \mathrm{que} \mathrm{no} \mathrm{le}$ figura «nada» $\mathrm{y}$ «donde él tampoco figura» (2000:37), en un espacio que no tiene «nombres»: «sólo cuando él recorre con el dedo una diagonal, la línea sale de sí, se hace autónoma y cae oblicua en el plano. El nombre dice por fin el diseño. Y el mono desanda ahora una forma» (Libertella, 2000:36). Sin nombre, sin posibilidad de apropiación, el mono camina por un espacio que tal vez ha sido espacio, no se apropia de él, no marca, pero realiza el gesto ancestral de señalar con el dedo la cosa, la «diagonal» que «cae oblicua en el plano» y dice «su diseño» para luego volver a desandar «una forma». La articulación ojo-mano-dedo-cosa se vuelve grama que desanda la forma; el camino, el trayecto retiene, en ese hender, aunque perturbada, la huella de su inscripción primaria. Si Hegel sostiene que se piensa en nombres, una iteración de la huella metamorfoseada del hender del dedo y de la mano, desaparecido el signo, borrado los límites del ghetto, el texto de Libertella disemina la impersonalidad, una transformación en cuyos efectos gravitan los hilos de la comunicación instantánea: «si los hilos de la Aldea hoy son invisibles — por 
satélites e inalámbricos—, el arte será doblemente invisible y silencioso en esa red, y la literatura un fantasma siempre un poco ilegible entre las líneas del mercado» (2000:21).

La impersonalidad da a leer el «fin del libro» en los textos de Mallarmé, reflexiona Sollers (1976:78), en ese tejido, el escritor no piensa y luego existe, se desplaza a «escribo, luego pienso en la pregunta: ¿quién soy?» (80). Esa operación de desvíos resulta de un leer como práctica desesperada en tanto maniobra que potencia la distancia crítica para proseguir, no con un abandonarse a representaciones, sino con un llevar al límite la escritura que consiste, más que en un cómodo expresar, en una intervención en el espacio invisible para volverse más invisible.

\section{Tercero. Fantasma}

El estar de un lado y del otro a la vez, el transformar los tiempos, los espacios y recorrer, mantener o rebasar las distancias, habilita la aparición del fantasma que perturba la inercia de una trayectoria. La reescritura — que implica, como se articula en este trabajo, lectura, apropiación, traducción, parodia, transformación - es la maniobra que asedia su aparición.

El fantasma, dice Derrida en Espectros de Marx, es siempre un (re)aparecido cuyo rastro insiste en ser localizado, identificado, incluso ontologizado aunque iterativamente se desvía sin dejarse aprehender. Sin embargo, la persistencia hace visible ciertas zonas y obsesiones que se despliegan como nudos condensados en constante desplazamiento. ¿Qué es seguir a un fantasma?, se pregunta Jacques Derrida, «¿y eso nos llevará a ser seguidos por él, siempre, a ser perseguidos quizás en la misma caza que queremos darle? Otra vez lo que parecía por-delante, el porvenir, regresa de antemano, del pasado, por-detrás» (2012:7).

En Memorias de un semidios (1998), la voz del protagonista se desdobla en narradores de distintas edades de Héctor Cudemo que relatan hechos en los que se encuentra presente ese otro narrador. Las memorias resultan de la confluencia y la distancia de la voz de Cudemo de quince años que, en primera persona, cuenta los acontecimientos que transcurren mientras ve (y narra) los sucesos de la vida de Cudemo adulto, casado con Nafka y dedicado a delinquir. Asimismo, el relato de Cudemo adulto narra las vicisitudes de su vida, su fuga constante de la justicia por el crimen del dueño del boliche Brassens de Mar del Plata, sus viajes en tren por el territorio argentino, sus visitas y caminatas por Nueva York y Massachusetts, distintas instancias del relato en las que se advierte la presencia de Cudemo de quince años, un joven traslúcido, como el Cudemo de veintidós años, protagonista de El camino de los hiperbóreos, que también aparece en el texto.

Así como en las primeras páginas de Memorias, Cudemo joven, «un joven extremadamente pálido», llega a Mar del Plata en el auto de unos turistas que dan miedo, en el que viaja Cudemo con su nodriza y su chofer; luego, en Brassens, ve a Nafka, su no aún futura «esposa», dentro de una jaula de vidrio, como una «imagen» del "porvenir» (1998:15); Cudemo adulto es testigo del viaje de Cudemo «joven", ambos viajan en el mismo auto, de Necochea a Mar del Plata, provocando un encimado de tiempos y espacios:

\footnotetext{
A la altura de Micaela Cascallares, alguien está haciendo dedo en la ruta, una persona de unos ¿veintiuno, veintidós años? Que parece traslúcida y sin consistencia, con una valija en la mano (...) Nuestro invitado se coloca en el asiento delantero, junto a Mario (...) Lleva una camisa blanca sucia, con el cuello deshilachado (...) Mi nodriza calla, por primera vez en la vida (...) Frente al Casino Central de Mar del Plata el tipo desciende por fin, valija en mano. (1998:59)
} 
Las figuraciones desdobladas no asedian o perturban al protagonista, trastornan la narración. En los traslados en espacio y en tiempo conviven los Cudemos, como sucede cuando, entre las localidades de «Bajo Hondo» $\mathrm{y}$ «Las Oscuras», Cudemo, desde el tren, ve «un bar mugroso y desierto en medio del campo, y adentro, encorvado sobre el piano, un joven de unos quince años parecía estar tocando un tango. También me hubiera gustado ser él» (1998:30), mientras, el joven toca el piano y a su espaldas «pasa un tren»; o cuando, en la fiesta de casamiento, en Manhattan, Cudemo ve a un chico que los observa con la nariz pegada al vidrio, que alude a Cudemo «joven» mirando a Nafka cuando aún no era su esposa.

En las distancias entre Cudemo adulto y Cudemo joven, la novela reescribe los motivos que se lee en la poética de Héctor Libertella: el campo argentino, la patagonia, el jardín de piedra y el neolítico, la red ferroviaria que atraviesa el territorio argentino, el ir más allá del gaucho argentino para recuperar lo araucano, la tensión entre el espacio argentino y el espacio de Nueva York y Massachussets, mediante una operación de ficcionalizar los procedimientos narrativos en las voces y acciones de los protagonistas:

\footnotetext{
$\mathrm{Al}$ atardecer habíamos agotado los motivos domésticos. Ahora hablábamos del porvenir como algo ya conocido. Barajábamos al infinito una misma escena congelada del pasado y le hacíamos lugar a un elemento que lo cambiara todo, aunque imperceptiblemente. Ludivina me describía una y otra vez el retrato familiar de los míos, hasta el cansancio, y de pronto en algún lugar aparecía asomando Yo.* De manera que el arte de la adivinación procedía por el agregado de un ínfimo dato en ese viejo tablero.

* El Mesías: «El que vino a dejarlo todo igual pero diverso» (28, énfasis propio)
}

\section{Como programa narrativo, Cudemo condensa rastros de Héctor Cudemo, protagonista de $E l$} camino de los hiperbóreos y de Virgilio Verga de Aventuras de los miticistas. Cudemo de Memorias, en su caminata por Manhattan, entra a «Tevies», la «tienda» en la que compra la «armadura antigua» que tematiza, en otra dirección, el motivo del fantasma.

En una jaula de vidrio colgante, por fin, estaba ella completamente desnuda, la armadura. Me miraba desde sus ojos de estatua como diciéndome «Soy Toda, y Tuya». Y yo me quedé mudo, mirándola. Cada una de sus partes y accesorios estaban rigurosamente indicados en un catálogo que se ofrecía adjunto: ALMETE, BARBOTE o BABERA, RISTRE, BUFA, GUARBRAZO, CODAL en su lugar, MANOPLA, QUIJOTAS O MUSLERAS, el GREBÓN, los ESCARPES. ${ }^{9}$ (70)

La armadura tiene inscripta el designio de la nodriza Ludivina: «Cuidado con tu armadura antigua, Héctor, que adentro de coraza siempre se ocultó mortaja» (1998:29) que preanuncia la muerte de Cudemo, cuando ambos viajan en tren, llevando prostitutas de un lado a otro de la pampa. Un morir que late en los ejercicios de levitación que realiza Cudemo en el Piano-bar «impulsado por el fantasma» (33), al que alude la adjetivación de Cudemo como «traslúcido» y al que conjura la foto que le toma el fotógrafo de Mar del Plata a Cudemo joven vestido con «camisa blanca», cuyo negativo arroja, en una "playa blanca», «una silueta de muerte vestida de negro» (60).

Vistiendo su armadura, una noche de carnaval, interceptado por la Interpol, Cudemo muere en las playas de Massachusetts, en las que no hay «ni una ráfaga de viento» (1998:107 sic), condición fundamental para que se produzca la levitación por «única vez para morir» (33 y 105). Ese 
fantasma por-venir, que va a venir, es reconocido por la policía, al igual que el fantasma del padre de Hamlet, que vestido con su armadura de pies a cabeza, es reconocido como tal por los guardias del castillo, incluso, cuando aun la armadura no deja ver el cuerpo, el rey puede «ver sin ser visto» (Derrida, 2012:22). A Cudemo, la armadura no lo disfraza sino lo delata como muerto vivo que es desde que guarda el revólver en la valija y sale de viaje rumbo a Mar del Plata, al inicio de Memorias. Ese levitar ${ }^{10}$ produce la transformación de lo por-venir, así como la muerte diseña retrospectivamente al espectro, si Derrida anota «Shakespeare qui genuit Marx, qui genuit Valéry» (2012:18), en Memorias se puede articular la serie: «revólver» qui genuit «armadura», qui genuit «muerte», qui genuit revenant o el que vendrá (re)aparecido. La armadura no es solo la de metal, es también la de letras y en la línea de la construcción ficcional, relaciona revenant con événement, en tanto evento que llega-regresa-de improviso, ¿llega de improviso?, no para Cudemo, ni tampoco para el lector, aunque esa espera no se explicite en el texto. Antes de morir, Cudemo adulto revisa la aparición de ese otro Cudemo que ve y se presenta en los acontecimientos de su vida:

¿Será un doble mío, acaso, que no creció en treintaipico, digamos treinta y nueve años? ¿Un bebé que sigue y sigue llorando desde aquel entonces lejano? Tampoco. Aquí la duda y las suposiciones están fuera de lugar. O ese lugar tanto lo ocupa mi cuerpo que hasta podría ser yo el que está llorando.

¿Tal vez se trate de un individuo que jamás vio el sol, alguien transparente como un negativo mirando al trasluz? (En el insomnio de mi cuarto me lo imagino velando sus armas como un caballero andante (...).

En tercer lugar, ¿es entonces un fantasma? Tampoco, aunque la muerte lo va diseñando de manera retrospectiva. A ver cómo. Uno saca del futuro lo que ya sabe de antemano y lo dispone a su alrededor para que al fin las cosas se cumplan sin sobresaltos. Por ejemplo: la coraza ya está comprada (...) uno ha dejado que los malentendidos y el enredo hayan llegado a tal punto que el desastre (...) tendrá que venir (...) uno abre la ventana de la habitación del piso 14 (...) y ve esas playas de Massachusetts (...) De este lado, estoy sólo yo, Héctor, Héctor Cudemo (...) no tuve ni tengo hermano gemelo, ni hay fantasma o doble mío que valga. (1998:100-101)

El asedio de la muerte y sus constelaciones semánticas como el morir, la levitación y la conversión en fantasma del protagonista, provocan desplazamientos; al desaparecer uno de los integrantes de la pareja autobiográfica Héctor Cudemo/Héctor Libertella en tanto programa literario que Libertella da a leer desde su primera novela publicada, el programa se transforma y reaparece como autobiografía: La arquitectura del fantasma (2006). La misma se abre con un fragmento como epígrafe que, en Memorias, aparece una y otra vez en el cuerpo del texto cuya confabulación de la muerte inevitable de Cudemo se inicia con la aparición de un cadáver por-venir. «Pienso en la muerte como un acontecimiento retrospectivo. Esa forma de irle pidiendo cosas al futuro para devolvérselas, al final, intactas. Como si uno no hubiera vivido. (Ya hablaremos de esto)» (1998:75).

Héctor muere pero levita como fantasma; a su alter ego, Virgilio Verga, le sucede lo mismo. Con el artista devenido (re)aparecido, lo narrado se desplaza a una autobiografía, una arquitectura que retoma algunos de los motivos de las itinerancias para volver a reescribir. En Mal de archivo, Derrida se pregunta qué es lo que Freud «ha podido querer guardar secreto o qué ha podido quemar en ese mal de archivo» (1997:106); en Memorias se quema, se mata, se muere y la huella levita transformada y convertida en un fantasma que asedia para reaparecer en otros trazos, en otros 
textos. No es casual que Libertella introduzca en La arquitectura del fantasma. Una autobiografía, la imagen de «La máquina de escribir» de Claes Oldenburg como «máquina de escribir fantasma» (1963) y como metáfora blanda de la plasticidad de la escritura. La cercanía y lejanía crítica en las operaciones de reescritura, las especulaciones narrativas y críticas y la ficción crítica, son maniobras con las que Libertella dinamita textos y literatura, no solo por las perturbaciones que provocan las palabras y los cortes en el espacio-tiempo de la cadena de sucesiones narrativas interrumpidas y/o estalladas, sino también por la incesancia del fantasma en las operaciones de reescritura.

\section{Cuatro. Distancia de rescate}

Encerrado, Libertella, mientras escribe su autobiografía, reescribe su obra, la distancia se mide en un cuarto de dos metros por tres y la desmesura se ciñe entre su cuerpo y sus textos. La arquitectura del fantasma. Una autobiografía, publicada en el mismo año que Libertella muere, 2006, da a leer cuatro cartas dirigidas al escritor cubano Lorenzo García Vega.

\section{Primera carta:}

Mi respetado y nunca bien ponderado Lorenzo. La cosa está. Es una enorme laguna, y a sus orillas un bebé muy viejo toma vacaciones, toma vacaciones a orillas de una laguna mental porque es muy viejo, el bebé. Y bebe. Todo el tiempo bebe un chablis frío, como sir John Gielgud en Providence. (2006:9 sic)

\section{Tercera carta:}

Escribo — como te anuncié — la biografía del viejo que pude haber sido (...) Hoy es el día exacto de mi cumpleaños, y no sé si estoy atrás o delante de lo que escribo. (2006:75, énfasis propio)

\section{Cuarta carta:}

Así que acá estoy, aislado desde hace ocho o nueve meses reescribiendo y achicando simultáneamente doce libros y eliminando otros tantos. Rumbo al impalpable cero. Encerrado en una pieza de dos metros por tres. Un amigo chistoso observaba ayer que yo camino mi pathos por una celda tan apretada como la horma de mis zapatos.

Mirá, Lorenzo, es un salto sin red abajo (...) Vos me entendés, es un viaje sólo de ida y al final te espera sir John Gielgud con un chablis en la mano. (2006:105, énfasis propio)

Antes de la cuarta carta y última página de la autobiografía, se lee un fragmento titulado «Buenos Aires, 21 de abril de 2006» que fecha el texto. Zettel es publicado póstumamente:

Hago y rehago Zettel con el cuerpo lleno de astillas. Recuerdo lo que ocurrió con Wittgenstein, esos papelitos — bisturí y tijera - que él dejó en una caja, seguramente sobras o proyectos de otros libros. Este Zettel va quedando con la modesta extensión de los aforismos, aunque furioso contra la soberbia de saber del aforismo. Y ojalá libre de la argumentación, una práctica tan esforzada que hoy por hoy ya genera aburrimiento (a mí; a mí ya me genera aburrimiento). (103, énfasis propio)

Libertella articula una poética que condensa y desvía genealogías que se enraízan en un cuerpo que se corporiza como escritura, como escritura del cuerpo y como cuerpo de escritura. En ese 
encierro, el bebé viejo reescribe y enhebra una «enorme laguna», las distancias no se miden en el espacio físico y geometrizado, tampoco con el concepto vulgar del tiempo, la «laguna mental» (2006:9), ineludible, potente, provocadora, «orilla» demoras y velocidades afantasmadas del «acá» y del «allá» del pro-yecto literario. La carta de Quartucci de 1971 y las dirigidas a García Vega de 2006, condensan un proceso en el que el escritor aparece como un poseso, aislado, asociando y disociando textos. Ese «todo abierto por delante» (2016:197), «el alfa y el omega» (1971:128), la provocación de la "tradición es posterior a mí» (1971:127), el espacio-puerto de Ingeniero White, la confluencia y disyunción de los Héctor Cudemo, el mono rhesus, el hembro, irradian y se conjugan en el trastorno y transformación de las categorías, del espacio, del tiempo, de la enunciación, de los personajes, entre otras nociones que mixtura el espacio literario y que Héctor Libertella plasma en su escritura, un salto sin red, de ida, y al final, «sir John Gielgud con un chablis en la mano»" —el fantasma llega de improviso.

La meta o extra-posición de Libertella traza su juego con las distancias como efecto de sus marcas y deslizamientos: norte-sur, ghetto, fantasma, cuarto propio, conforman divergencias, desvíos, inscripciones y correlaciones cuyas pregnancias se vierten en grafías que rompen, aun en ella, el modelo enigmático de la línea. Un leer/ver desesperado, poseído por un trabajo que arma y desarma, el cuarto es Nueva York, el dos por tres, el mundo, la escritura, el límite se ha desplazado o se ha vuelto doblemente invisible.

\section{Notas}

1 Escribe Heidegger en El sery el tiempo que a ese «advenir presentando que va siendo sido» es lo que llama «temporalidad» y prosigue: «El uso de esta expresión como término técnico ha de alejarse antes que nada de todas las significaciones de "futuro", "pasado" y "presente" que sugiere el concepto vulgar del tiempo. Dígase lo mismo de los conceptos de un "tiempo" “subjetivo" y “objetivo" o “inmanente" y “trascendente”» (354). En el Apartado 70, se lee: «Aunque la expresión "temporalidad" no significa lo que se entiende por tiempo cuando se habla de "el espacio y el tiempo", también la espacialidad parece constituir una determinación fundamental del "ser ahí" paralela a la temporalidad» (2004:396).

2 La crítica filosófica señala las dificultades especulativas del proyecto de Heidegger en El sery el tiempo, que lo obliga a su abandono, no obstante, me interesa señalar con esta aproximación, un modo de consideración del tiempo y del espacio que difiere del «concepto vulgar» que domina la Física de Aristóteles hasta la Lógica de Hegel, como señala Jacques Derrida en De la gramatología. Hubert Dreyfus establece un cuadro comparativo entre «espacio» $\mathrm{y}$ «espacialidad», en el texto de Heidegger, estructurando la siguiente oposición: «Espacio físico: Espacio geométrico, el espacio de lo presente.
Homogéneo, sin centro. Extensión pura. Multiplicidad tridimensional de posiciones. Mediciones de distancia»; «Espacialidad existencial. Espacio vivido, el espacio disponible. Personal: centrado en cada uno de nosotros. Orientación (arriba-abajo, derecha-izquierda). Lejanía/cercanía de los objetos. Público: tienen regiones y en estas, lugares. Grado de disponibilidad» (2002:110).

3 El modelo liberal generó el exterminio de los pueblos originarios que habitaban el territorio argentino e instaló un modelo agro-exportador mediante la expropiación y la repartición de las tierras entre ricos terratenientes. El efecto de decadencia — de esplendores decrépitos, de osamenta de vacas, de indios alcohólicos y tuberculosos, del enterramiento subterráneo de la riqueza patagónica — se relaciona con las consecuencias que produjo ese modelo.

4 Se utiliza ese término en el sentido de estancamiento y paralización, como lo define Aníbal Quijano (1988).

5 La pastoral articula un conjunto de transposiciones imaginativas producto de la mirada de un sujeto que responde a un régimen anti-utilitario y construye un «paisaje» como resultado de una mirada distanciada. Expresa, por lo tanto, una tensión en relación con la propiedad y el dinero, 
con cuestiones de poder y despojo, en esa dirección, Raymond Williams (2001) sostiene que la pastoral de Teócrito y Hesíodo exhibe tópicos que se diferencian de la del capitalismo agrario, del pasatiempo cortesano, de la casa solariega, entre otras (ver El campo y la ciudad).

6 Agamben postula que el «ser que viene» es el «cualsea»: «el cualsea que está aquí en cuestión no toma, desde luego, la singularidad en su indiferencia respecto a una propiedad común (a un concepto, por ejemplo: ser rojo, francés, musulmán), sino solo en su ser tal cual es. Con ello, la singularidad se desprende del falso dilema que obliga al conocimiento a elegir entre la inefabilidad del individuo y la inteligibilidad del universal. Pues lo inteligible, según la bella expresión de Gerson, no es ni el universal ni el individuo en cuanto comprendido en una serie, sino la singularidad en cuanto singularidad cualsea. En esta, el ser-cual está recobrado fuera de su tener esta o aquella propiedad, que identifica su pertenencia a este o aquel conjunto, a esta o aquella clase (los rojos, los franceses o los musulmanes); el ser-cual está retomado no respecto de otra clase o respecto de la simple ausencia genérica de toda pertenencia, sino respecto de su ser-tal, respecto de la pertenencia misma» (1996:8-9).

7 Agamben, leyendo a Heidegger, señala en relación con el «así»: «Ser-así; ser el propio modo de ser: esto no podemos aferrarlo como una cosa. Esto no es, por tanto, más que la evacuación de toda coseidad. (Por esto, los lógicos indios decían que el ser así — sicceitad — de la cosa no es sino su ser privado de una naturaleza propia, su vacuidad, y que entre el mundo y el nirvana no hay la más mínima diferencia)» (71). En otro fragmento agrega: «Así sea. En toda cosa afirmar simplemente el así, el sic, más allá del bien y del mal. Pero así no significa simplemente: en este o aquel modo, con aquella cierta propiedad. "Así sea" significa: sea el así. Esto es: sí. (Este es el sentido del sí de Nietzsche: el sí se dice no simplemente a un estado de cosas, sino a su ser-así. Sólo por esto puede regresar eternamente. El así es eterno)» (1996:72).

8 No hay fijeza en Árbol, cada frase o predicación puede ser negada o suspendida a la palabra siguiente.

9 Esta descripción cobra relevancia nuevamente en la serie narrativa en torno a Hernando de Magallanes y en el dibujo de Eduardo Stupía que aparece en El lugar que no está ahí.

10 Según la RAE, del inglés levitation, y este der. del latín levitas, -ātis, «ligereza», «falta de peso». 1. Dicho de una persona o de una cosa. Elevarse en el espacio sin intervención de agentes físicos conocidos. 2. f. Sensación de mantenerse en el aire sin ningún punto de apoyo.

11 En Providence, el film de Alan Resnais, protagonizado por John Gielgud, Clive Langham, su protagonista, es un viejo escritor que toma litros y litros de alcohol mientras febrilmente combina y recombina las vidas de sus familiares, de una y otra manera. La voz de Langham replica en una voz innominada y amalgamada en El paseo internacional del perverso que anuncia «de un trago al otro, y en la distancia que va $18^{\circ}$ a $36^{\circ}$, me ataca el furor de cambiarlo todo» (Libertella, 1990:89).

\section{Referencias}

Agamben, G. (1996). La comunidad que viene. Valencia: Pre-Textos.

Derrida, J. (1971). De la gramatología. Argentina: Siglo XXI.

Derrida, J. (1997). Mal de archivos. Madrid: Trotta.

Derrida,J.(2012). Espectros de Marx. El trabajo de la deuda, el trabajo del duelo y la nueva internacional. Madrid: Trotta.

Dreyfus, H.L. (2002). Ser-en-el-mundo. Chile: Cuatro vientos.

Heidegger, M. (2004). El sery el tiempo. Buenos Aires: Fondo de Cultura Económica.

Jitrik, N. (2006). Rehabilitación de la parodia. Para leer la parodia. Buenos Aires: FILO.

Libertella, H. (1968). El camino de los hiperbóreos. Buenos Aires: Paidós.

Libertella, H. (1971). Aventura de los miticistas. Caracas: Monte Ávila.

Libertella, H. (1990). El paseo internacional del perverso. Buenos Aires: GEL.

Libertella, H. (1998). Memorias de un semidiós. Buenos Aires: Perfil.

Libertella, H. (2000). El árbol de Saussure. Una utopía. Buenos Aires: Adriana Hidalgo.

Libertella, H. (2003). La librería argentina. Córdoba: Alción.

Libertella, H. (2006). La arquitectura del fantasma. Una autobiografía. Buenos Aires: Santiago Arcos. 
Libertella, M. (2013). Mi libro enterrado. Buenos Aires: Mansalva.

Moreno Romo, J.C. (2013). El sentido y la distancia. Entrevista a Jean Luc Nancy. Open insight, IV(5), 183-211.

Paz, O. (2014). El mono gramático. Barcelona: Seix Barral.

Quartucci, G. (2016). Héctor Libertella. Carta desde Nueva York. En López, S. Libertella/Lamborghini (pp. 193-198). Buenos Aires: Corregidor.

Quijano, A. (1988). Modernidad, identidad y utopía en América Latina. Imágenes desconocidas (pp. 29-45). Buenos Aires: CLACSO.

Rancière, J. (2010). El espectador emancipado. Pontevedra: Ellago.

Rojas Paz, E.P. (1968). Héctor Libertella: un premio literario sin literatura. ArteTiempo, 1(2), 16-17.

Sarlo, B. (2007). Una modernidad periférica: Buenos Aires 1920 y 1930. Buenos Aires: Nueva visión.

Sollers, P. (1976). Literatura y totalidad. La escritura y la experiencia de los límites (pp. 77-98). Caracas: Monte Ávila.

Williams, R. (2001). El campo y la ciudad. Buenos Aires: Paidós. 
